The University of Maine

\title{
DigitalCommons@UMaine
}

Anthropology Faculty Scholarship

Anthropology

2012

\section{On the Politics of Climate Knowledge: Sir Giddens, Sweden and the Paradox of Climate (In) Justice}

Cindy Isenhour

University of Maine, Department of Anthropology, cynthia.isenhour@maine.edu

Follow this and additional works at: https://digitalcommons.library.umaine.edu/ant_facpub

Part of the Anthropology Commons, Behavioral Economics Commons, and the Environmental Policy Commons

\section{Repository Citation}

Isenhour, Cindy, "On the Politics of Climate Knowledge: Sir Giddens, Sweden and the Paradox of Climate (In)Justice" (2012). Anthropology Faculty Scholarship. 4.

https://digitalcommons.library.umaine.edu/ant_facpub/4 
Isenhour, Cindy. 2010. On the Politics of Climate Knowledge: Sir Giddens, Sweden and the Paradox ofClimate (In)Justice. Local Environment: International Journal of Justice and Sustainability 17(9).

\section{On the Politics of Climate Knowledge: Sir Giddens, Sweden and the Paradox of Climate (in)Justice}




\begin{abstract}
There is a widespread assumption that most people will not effectively respond to climate risk until they personally experience its negative effects. Yet this assumption raises some interesting questions in the Swedish context. The majority of Swedes say they have not experienced the negative effects of climate change, but they are among the world's citizens most concerned about and active on the issue. These observations raise the question - why do many Swedes act progressively if they do not feel environmental risks “closer to home”? Is there something exceptional about Swedish environmental ethics, political culture or governance structures? This paper explores these questions, using the Swedish case to challenge essentializing concepts like “Giddens’ paradox” which, too often, equate risk perception with self-interest, neglect concern for climate justice and depoliticize climate knowledge. This research suggests that concern for climate justice, rather than self-interest, proves to be a more powerful motivator for climate action in the Swedish context and potentially beyond.
\end{abstract}

\title{
Keywords
}

[climate knowledge, risk, sustainability, consumption, environmental justice, political ecology] 


\section{Introduction: Are Swedes Immune to Gidden's Paradox?}

Despite many attempts to mitigate greenhouse gas emissions and strong evidence to suggest the need for more urgent and substantial action, total global emissions are on the rise (Peters et. al. 2011). It is in this context that a growing number of scholars have sought to explain why we - as a global society, as nations, as communities, and as individuals -- have not taken more meaningful actions to prevent climate change. Myriad explanations for inaction, apathy and political stalemates have been put forward by scholars and public commentators alike (Gifford 2011). In this paper I focus on one of the most prevalent explanations. Based on insights from psychology, these ideas suggest that people are more likely to respond to climate change if they have personally seen, felt, or experienced its negative effects

(Weber 2006, Brody et. al. 2008, Spence et.al. 2011, Semenza et. al. 2011). Certainly, these ideas would seem to explain recent public opinion polls which show that extreme weather events are strengthening perceptions of climate risk in many international contexts (Leiserowitz et. al. 2012).

Prominent sociologist Sir Anthony Giddens has drawn on these long-standing insights, appropriating and naming them his own - the “Giddens’ Paradox” (Giddens 2009). He argues that by the time people feel the negative effects of climate change, it may be too late. He writes,

No matter how much we are told about the threats, it is hard to face up to them, because they feel somehow unreal - and, in the meantime, there is a life to be lived, with all its pleasures and pressures. The politics of climate change has to cope with what I call Giddens' paradox. It states that, since the dangers posed by global warming aren't tangible, immediate or visible, in the course of day-to-day life, however awesome they appear, many will sit on their hands and do nothing ... about them (2009:2). 
Certainly personal experience can change perceptions and motivate action as psychological research has suggested, but is personal experience a necessary condition for action as Giddens seems to suggest in his framing of “The Giddens’ Paradox? I explore Giddens’ paradox in this paper because it raises a number of interesting questions in the Swedish context where, despite the fact that the majority of Swedes do not report experiencing the negative effects of climate change or perceptions of personal risk, both the state and the citizenry have acted proactively, relative to other wealthy post-industrial societies. If Giddens’ paradox is so pervasive, why do many Swedes continue to act if they do not feel environmental risks “closer to home”? I argue here that we can answer this question in two ways. First, through an examination of the Swedish context, we see how factors like a history of ethnic homogeneity and the ideology of the social welfare state have interacted with Sweden's consensual political culture and their interntional identity as a global mediator to foster a cosmopolitan worldview and citizens that are highly motivated by concerns for global climate justice. The case clearly illustrates that despite the universal claim of Gidden’s paradox, risk perception and response are, at least in part, culturally influenced social constructions. Secondly, and perhaps more importantly, I argue that we need to rethink generalized theories like Giddens’ Paradox, particularly as they are appropriated inpopular discourse. Without revision, I argue that Giddens’ Paradox has a dangerous tendency to equate risk perception with self-interest, to neglect concern for climate justice, to enable self-fulfilling prophesies of inaction and to depoliticize climate knowledge.

\section{Context for a Paradox?: Researching Swedish Environmentalism and Governance}

The Swedish case raises many interesting questions about the links between personal experiences, risk perception and climate action. . Sweden has consistently expressed the desire to lead the international shift to sustainability (Matti 2009), setting environmental quality goals and 
institutionalizing a system of green indicators to measure improvements (Jörby 2001). Yale \& Columbia Universities' Environmental Performance Index has consistently ranked Sweden among the world's "Strongest Performers" on environmental issues (EPI 2012). This is, in part, due to a carbon dioxide tax instituted in 1991 that is widely credited with inspiring a significant shift away from fossil fuels (ㅌouché 2008) and contributing to a $10 \%$ reduction in GHG emissions between 1990 and $2010^{1}$ (Naturvardsverket 2012). Further, Sweden's Local Investment program and investments in district heating have helped to modernize buildings and infrastructure and thus improve energy efficiencies. On a local level, Sweden's capital Stockholm implemented one of the world's first traffic congestion tax schemes in 2007, which has been credited for a 14 - 18\% reduction in CO2 emissions within the city's limits (Stockholmstad 2009). These efforts have enabled Sweden to significantly reduce the carbon intensity of its economy. Behind Luxembourg, Sweden leads the world in this regard, reducing carbon dioxide emissions per GDP by 72\% between 1972 and 2007 (TCO 2012). While other European nations have outperformed Sweden in total GHG reductions (EEA 2012), Sweden likes to point out that, on a per capita basis, their emissions are among the lowest in EU-27 (5tons/person compared to 7.5 tons, on average, for the EU-27) and that their reductions did not come at the expense of economic contraction (Eurostat 2012).

While Sweden's state-led ecological modernization programs and policies led to significant reductions, research suggests that many of these improvements were outstripped by growth in the emissions associated with private household consumption (Naturvårdsverket 2010),. As the result of this realization and in concert with the growing influence of market-based environmental solutions (Author 2010, Matti 2009), the nation has increasingly moved away from their focus on state-led infrastructural and production-orientated approach and toward market-based programs centered on

\footnotetext{
${ }^{1}$ It is interesting to note that in 2008 Swedish GHG emissions levels were $17 \%$ below their 1990 levels, marking the lowest point in a progressive downward trend. However, 2010 marked a reverse in this trend due to the effect of an extremely cold , record breaking winter and economic recovery.
} 
consumer responsibility and sustainable lifestyles (Matti 2005). Sweden’s Environmental Protection Agency (Naturvårdsverket) and Consumer Agency (Konsumentverket) are only two of the many governmental agencies that have designed programs urging Swedes to "buy green" and take responsibility for their carbon emissions and the environmental impacts of their lifestyles.

Mainstream environmentalism is well documented among the Swedish citizenry (Frykman \& Löfgren 1987, Löfgren 1990) and many Swedes have accepted the call to live more sustainably by driving less, buying organic foods, recycling, and conserving energy in their homes or shopping second hand. Compared to the citizens of other European nations Swedes report relatively high levels of boycotting for environmental reasons, purchasing ecolabeled and organic products, and proper disposal of hazardous wastes (OECD 2012, Micheletti 2003, Ferrer \& Fraile 2006). There is also a strong political and scientific consensus about climate change in Sweden. According to the Swedish Environmental Protection Agency’s 2009 study on public attitudes toward climate change, 89\% of Swedes consider themselves climate conscious. As a result, 80\% report efforts to reduce energy consumption at home, 66\% report changing their travel patterns and nearly half have changed their eating habits due to concern for the climate (Naturvårdsverket 2009).

While a strong and mainstream environmental movement is common in many different national contexts, and there is certainly significant variety within Sweden, EuroBarometer studies reveal that as a whole Swedes place more emphasis on environmental issues than the citizens of other EU countries. In fact, in the most recent Eurobarometer survey, 20\% of Swedes listed environmental/climate issues as one of the two most important issues facing their nation. While this number might seem low, it is significant in the context of an ongoing economic recovery. It is even more notable when we compare Sweden's prioritization of environmental issues against the rest of the EU-27 respondents, only 4\% of whom listed environmental/climate issues as one of the two most important issues facing their country 
(EC 2012). This concern for climate was present in Sweden even during the worst periods of the global financial crisis. In early 2009, 82\% of Swedes responded that climate change was the most serious problem facing the world as a whole. This can be compared to $50 \%$ of the total EU-27 sample (EC 2009). Strong concern for the climate is also expressed in Sweden's domestic political realm where the Green Party recently became the third largest party in Parliament. Swedes also prioritize the fight against climate change and other environmental issues in their ideas for improving the EU. Yet according to the European Commission, "Europeans in general do not share the enthusiasm of Swedes...sometimes, it would appear that the Swedish media believe that opinions on environmental issues and climate change are much the same throughout Europe. This may create exaggerated expectations on the European Union's ability and political will to address these questions” (European Commission 2009:72). While it is important to make the point that Swedes do appear to be more concerned and active on the climate relative to other wealthy post-industrial nations, , it is important not to romanticize Sweden or Swedish consumers. Despite the efforts of many citizen-consumers, industry, governmental and non-governmental organizations, sustainable consumption patterns have failed to emerge. Swedes are privileged consumers with impressive carbon footprints. Approximate half of all carbon emissions in Sweden are generated by private household consumption (Naturvårdsverket 1996). On average each Swedish citizen emits 5.6 tons of carbon dioxide every year (Naturvårdsverket 2007). While these levels are lower than the EU 27 average of 7.5 tons (Eurostat 2012) and do not compare to the footprint of the average American citizen (20-25 tons of carbon dioxide annually), they are far above what is believed to be sustainable (GFN2009). However, it is clear that Swedes do take the issue of climate change seriously and that many have acted proactively to mitigate emissions.

In order to explore Swedish concern for the climate and environment more generally, and to explore questions about why Swedes are so concerned about the climate relative to their European 
neighbors and the rest of the world, I spent 14 months engaged in fieldwork in Sweden. Because the population of citizen-consumers concerned about sustainability was unknown, I drew upon Haraway's (1991) concept of affinities to identify five organizations working on sustainability. A call for participants was sent to their members, resulting in 9 to 14 volunteers from each who participated in a semi-structured interview. In total 58 individuals, primarily from the Stockholm area, its suburbs and rural areas with a 150 mile radius, participated in this segment of the research . Twelve of these participants and 14 of their family members were also selected to participate in case-study household research which included a review of household expenditures, consumption inventories, and a series of iterative interviews. Finally, the methodology also included semi-strucured interviews with 31 representatives from 24 governmental, non-governmental and academic institutions working on sustainability issues. Through this research I aimed to understand how people in wealthy post-industiral urban and semi-urban settings - most of whom were far removed from direct connections to the land, control of productive resources, or environmental feedbacks - came to understand climate change and other threats to sustainability. I also aimed to explore how alienation from productive resources and decisions about their use conditioned and limited attempts to respond to concerns for environmental health given their limited sphere of influence ${ }^{2}$.

\section{How to Explain Climate Concern and Skepticism?}

If we accept Gidden's Paradox wholesale, without attention to alternative explanations, then we would assume that Swedes have responded so progressively to climate change because they have personally experienced or witnessed its effects "in the course of day-to-day life". However my ethnographic research in Sweden does not provide support for this explanation. Neither do other empirical studies based on survey data. A 2007-2008 Gallup Poll, for example, examined views about

\footnotetext{
${ }^{2}$ To understand these views on sustainability and corresponding actions, I also explored the context of sustainability in Sweden via policy reviews and interviews with 31 representatives of 24 governmental and non-governmental organizations.
} 
climate change in 128 countries. The survey found that while US and Swedish citizens are both highly aware of the issue of climate change ( $97 \%$ and $96 \%$ respectively), Swedes are less likely than Americans to consider global warming a "personal threat" at 56\% compared to 63\% (Gallup 2008),. So, if personal experiences and perceptions of "personal threat" constitute the means for action, then shouldn't the US be more proactive? The evidence certainly doesn't seem to support this assertion. Carbon dioxide emissions in the US increased by 17\% between 1990 and 2007 (EPA 2012) while Sweden reduced their emissions over the same time period (Naturvardsverket 2010). Further, on a percapita basis, the average American has a carbon footprint that is more than double the size of the average Swede’s (GFN 2010).

My ethnographic research also indicates that Swedes who are trying to live more sustainably do not demonstrate Giddens' paradox. During interviews, research participants were asked a series of questions about environmental risks. Their answers illustrated significant variety. Some were concerned about chemical preservatives in food, others about species extinctions, environmental refugees, soil erosion or environmental injustices. However when considered in aggregate, it is apparent that nearly all research participants shared a common concern for climate change, the effect of toxic pollutants, resource depletion and the social and economic effects of scarcity and inequality. The word cloud in Figure 1 illustrates the frequency with which these concerns were mentioned by research participants. The larger the word, the more frequently it arose in conversations. 


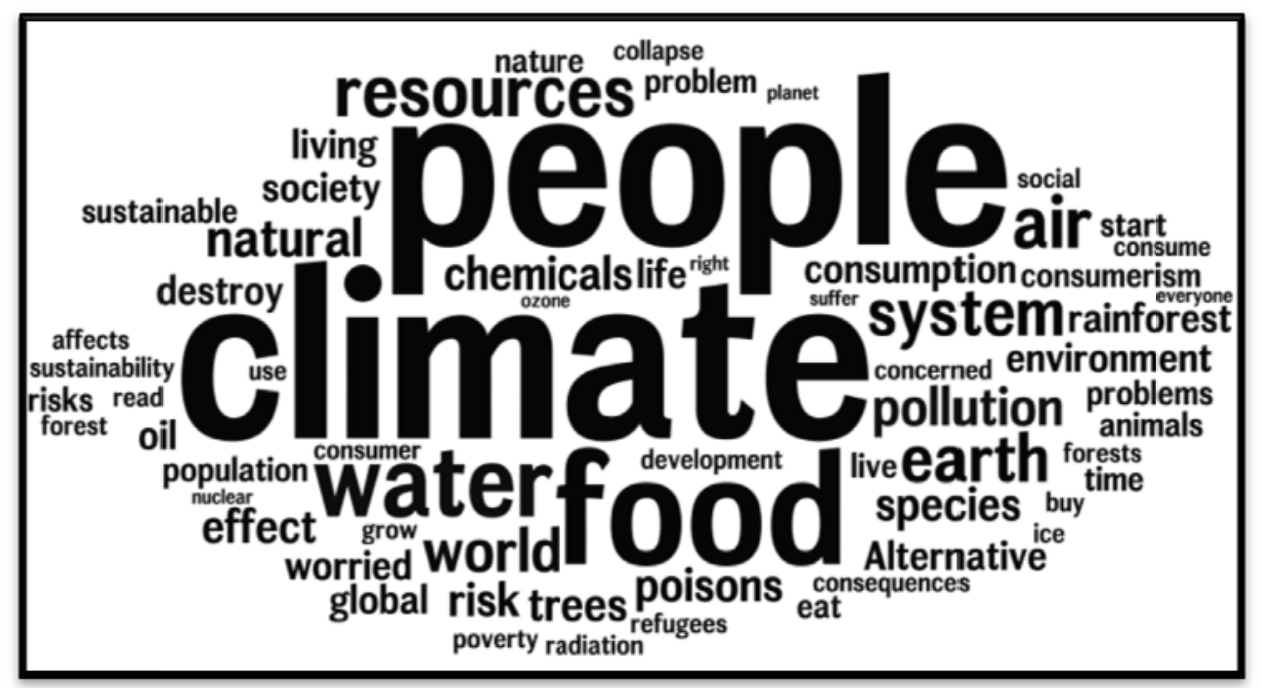

Figure 1: A Wordle $($ Word Cloud Representing Frequency of Environmental Concerns

Key words like climate, people and food were mentioned often, illustrating that many research participants were concerned about the impact of climate change on agriculture, anticipating that significant changes could affect our ability to produce enough food. Also note the prominence of "people" in the figure, a very important theme in the context of this paper, to which I will return momentarily.

What is perhaps most interesting given our discussions here, is that when these people were asked whether they felt personally affected by these issues, the majority of the respondents answered that they did not. Because the Swedish population is concentrated near sea level, there is clear risk associated with climate change. Models also suggest that, due to ice melt from Greenland, the Gulf Stream will likely be disrupted, resulting in colder weather for Northern Europe. Despite these projections, only 21 percent of the sample felt they were being directly affected by environmental problems, speaking most often of issues unrelated to climate change - including the health risks of chemicals in foods or poor air quality on busy thoroughfares. In the specific case of climate change, this can be compared to a nationally representative survey which revealed that while $98 \%$ of Swedes believe that Sweden will eventually be affected by climate change, only $52 \%$ felt that Sweden has already 
experienced its effects (Naturvårdsverket 2009). This percentage is even lower among the sample of environmentally-concerned and active Swedes participating in this research, 76\% of whom said they had not felt personal risks but were rather concerned about the effects of environmental problems on people in the third world or on members of future generations.

One research participant centers her motivation for personal action on her concern for those who would be most affected by climate change, saying,

I'm not at all worried about me, and I don't think that I'm worried about the future...more that we are sitting here and consuming a lot and destroying while people in other parts of the world can't get enough to eat. We are taking their resources and we are making them grow crops that we need instead of food for them. I think that is my biggest concern, but I don't feel any risk to myself.

In contrast to those who feel no personal risk but do a lot to live more sustainably, research participants who perceived personal risk were often the least progressive in their behaviors. All research participants were asked to help make a list of all the things an individual could do to live more sustainably. These "domains" of sustainable living were then aggregated, generating a list of 151 unique actions ranging from the conceptual, like "rethink your priorities in life" to the specific and pragmatic like "compost egg shells" and "turn the water heater down". These ideas were then grouped into 20 categories by the author and several research participants (Table 1).

Finally, research participants were asked to evaluate how good they were at doing each of the items on their list. There was significant consensus among research participants on many categories of sustainable action, yet at an individual level the free lists revealed considerable diversity. While some research participants were difficult to pigeon-hole as either individualist or collectivist in their concerns and objectives (Lee et.al. 2009, Binkley 2009), others clearly fit into this dichotomy. Some "light 
green” (Wissenburg 1993) participants were clearly more concerned about their family's health and translated that concern into actions like buying organic food and natural products. Others worried more about the economic and social impacts of peak oil and thus were more likely to list actions related to energy efficiency, self-sufficiency and alternative technologies. Meanwhile many of those concerned with global solidarity, environmental justice and poverty mentioned efforts like boycotting unethical corporations or the consumption of fair trade foods and sweat free clothing

Most relevant to our discussion of Gidden's Paradox is that the relationship between participants' domains of sustainable action, their actions, and their perceptions of risk reveal an interesting pattern. Those who perceived risk primarily to others, future or present, listed sustainable actions in nine different categories on average. In contrast, those who felt immediate risk to self and family listed fewer absolute actions, associated with only six categories. Thus the domain of sustainable living appears to be more restricted for those who have responded to perceptions of personal risk ${ }^{3}$. These individuals were much more likely to focus on the purchase of more environmentally friendly "green" goods when available and convenient. In contrast, 55 percent of those who felt that risk was concentrated elsewhere listed actions not only related to buying more "ecofriendly" goods, but they were much more likely to list actions in the citizenship category including voting, joining activist groups, contacting politicians, or demonstrating (compared to 25 percent for those who feel personal risk). Finally, those concerned about consumerism's impacts on others were also much more likely to list actions associated not only with buying green, but also with buying less (91 percent compared to 50 percent of those who perceive personal risk). The research therefore suggests that the Swedes who have made the most progressive lifestyle changes are more likely to be driven by concerns for equality and

\footnotetext{
${ }^{3}$ A t-test revealed with $99 \%$ certainty that the difference between the number of categories listed by these groups was statistically significant with a t-value of 2.68 .
} 
the fair distribution of environmental risks and benefits than perceptions of personal risk (Author 2010).

This insight would suggest that Gidden's paradox is not always applicable in the Swedish case. The people who participated in my study haven’t acted progressively because they've witnessed or experienced the negative effects of climate change. In fact, they were much more likely to be driven to significant lifestyle change based on their concerns for others and environmental justice. In the pages to follow, I explore how to best explain this deviation from the Gidden’s Paradox. I argue that we can explain it, in part, as the product of a specific Swedish history and thus also through a critique of generalizing and universalizing ideas, like Gidden's paradox, that have a tendency to depoliticize, decontextualize and dehistoricize our understandings of risk perception and response.

\section{Explanation I: Swedish History \& the Concern for Global Environmental Justice}

I was surprised and overwhelmed when conducting interviews by how many people expressed the need for solidarity and global equality as part of any program designed to reduce emissions and ensure sustainability. These people clearly saw their actions as part of an agenda to consume and emit less so that people in low income economies would have the ability to consume and emit more. I met Mats, a research assistant in his late twenties, at one of Stockholm's public meeting spaces late one evening. While it was clear that he was passionate about sustainability, his perspectives were measured and thoughtful. Mats doodled on a pad of paper as he spoke about human impacts on the environment and the injustices of resource inequality. His work at the agricultural university in Uppsala, researching sustainable agricultural policy, had already required his reflection on many of the topics covered during our conversation. Yet throughout the conversation a common theme emerged, Mats' deep concern for global solidarity. While speaking about the most promising solutions for ensuring sustainability, he focused on political strategies, saying, 
Every human being should have the right to an equal use of nature and resources, you know. I really think equality is important and I don't see why any human being should have the right to consume more than anyone else. And that's on a global level, so that would mean a reduction in consumption in rich parts of the world. We tend to just look at Sweden, and the environment is good here. We blame China for all their emissions. But it is our consumption, our taking too much that is driving their emissions. They are producing for us. We can't view these things separately on a country-by-country basis. We need to understand that many barely have enough and we take more than our fair share.

Mats' comments are representative of a widespread and clear emphasis on equality within the sample. This orientation is also gaining recognition withinin the Swedish government due to the efforts of many environmental groups including Friends of the Earth Sweden. In 2008, the Swedish Environmental Protection Agency released a report entitled “The Climate Impacts of Swedish Consumption” which moved beyond discussions of emissions reductions in Sweden to examine the total effect of Swedish consumerism globally. Instead of claiming that Swedes have reduced carbon emissions by nearly $10 \%$ since 1990 (Naturvårdsverket 2008), the government is now taking an active role investigating and calculating emissions in other lands that can be attributed to Swedish consumer demand. This new focus is not only consistent with the prevalence of life-cycle analyses in the Nordic countries, but it also reflects a concern with global equity and responsibility. There are also a few other governmental documents that advocate consuming less so that people in impoverished areas around the world can have more. One document produced by Sweden’s Consumer Agency entitled "Environment for Billions" (Konsumentverket 2001), points to research which suggests that wealthy industrialized countries like 
Sweden would have to reduce consumption by a factor of ten for every human being on the planet to have equal access to the world's resources.

While this emphasis on equality is not unique to Sweden or Scandinavia, and is certainly not shared by all Swedes, it makes sense given the region's political history. There is a pervading sense of middle class morality, solidarity and the need for equality within Nordic culture, inspired by the historical teachings of the Lutheran Church and perpetuated by the ideologies of the welfare state. Scholars have theorized that the emphasis on equality in the region is tied to populations which were relatively ethnically consistent with state boundaries, thus fostering support for ideologies of equality, fairness, corporatism, and class-based politics. And while it is certainly not the case that all are truly equal in Sweden, (particularly given the recent influx of immigrants of Arabic ethnicity and Islamic faith and the corresponding growth of Islamaphobia and nationalist parties throughout Scandinavia) the ideology and rhetoric of equality continue to inspire domestic policies that support class-based leveling. Sweden's GINI coefficient is among the lowest in the world and the government has historically worked to foster an ideology of solidarity, equality and equal rights (Epsing-Anderson 1992).

Sheila Jasanoff (2010) argues that political culture goes a long way in explaining our views on climate change. Comparing the US and European nations, she observes that climate skepticism in the US is not surprising given its contentious political culture. Nations with consensus-seeking epistemologies, like those that characterize Scandinavian politics, are more likely to consider multiple viewpoints and move beyond political stagnation. Swedish political culture is characterized by a participatory corporatist model, a form political scientists link to more dynamic and greener policy agendas (Broadbent 2009). In fact some of Sweden's most progressive environmental policies are the product of cooperative efforts between industry, academia, non-governmental organizations, the 
Swedish Church and the Rikstag. This political culture can be attributed, in part, to Sweden's global position in recent history as an international mediator. As early as the Bolshevik revolution in Russia, Sweden began to think seriously about developing a "third way" model that could balance concerns for equity and opportunity with economic growth and prosperity. Their social democratic model has enabled a strong and competitive capitalist economy to exist in tandem with a robust social welfare system. This "third way" approach has fostered a consensual political culture that operates both domestically and in international negotiations.

The work of Daniel Kahan and his colleagues at the Yale Cultural Cognition Project has empirically demonstrated that societies and individuals with more communitarian worldviews are much more likely to believe in climate change than those with a more individualist cultural ideology. In fact, the cultural cognition framework reveals that these cultural orientations are among the strongest predictors of climate belief and action (Kahn, Jenkins-Smith \& Braman 2011). Certainly it is possible that Sweden's long history of communitarian domestic policy has created openness to these viewpoints on an international scale and influenced climate perception and action. Perhaps that is the reason why Swedes have been so proactive in the absence of personal experiences with climate risk.

\section{Explanation II: \& the Need to Reframe Climate Knowledge in Global Context}

Yet our first explanation raises the question of whether Sweden is a unique case, an exception to the otherwise sound observation that most people will not act until they are personally at risk. Or, perhaps, is there a flaw or problematic assumption in Giddens' paradox? It is difficult to take issue with empirical observations that peopleare more likely to act if they have personal and localized experiences of risk - but these observations do not necessarily support Gidden's claim that most will not act until the dangers posed by climate change are "tangible, immediate, or visibile" in our daily lives. 
Phychological research indicates that humans make decisions based on both affective (emotional, experience-based and localized information) and analytical (scientific, second-hand, expert generated) information (Swim et.al. 2011). In the cases of risk and uncertainty, this research suggests that individuals are more likely to act if they have personal, affective knowledge of the risk. Thus the idea is that affective information linked to emotions is more motivating than abstracted analytical information like projected sea-level rise or parts per million concentrations of green house gasses. Citing Weber (2006), Swim and her colleagues have written,

Climate change appears to be an example where a dissociation between... the analytic and the affective systems results in less concern than is advisable, with analytic consideration suggesting to most people that global warming is a serious concern, but the affective system failing to send an early warning signal (Swim et. al. 2011:23).

My argument is not that spatial and temporal discounting do not occur. Research makes it clear that they certainly do in many different contexts (Uzell 2000, Gifford et. al. 2009). However, where Giddens and many others go wrong is assumption that climate knowledge must be tied to localized experiences of personal risk to be effective motivators for change.

. Education and acceptance of analytical data, paired with Scandinavia’s interest in equity certainly can provide part of the explanation for their proactive stance on the climate. Yet we also know that decades of informational and awareness campaigns designed to appeal to self-interest, in Sweden and throughout the EU, have failed to result in sustainable greenhouse gas emissions among the majority (Author 2010, Whitmarsh 2011). I therefore argue that the Swedish case brings to light several problems associated with Giddens' framing of his paradox. First, the insight that people are more likely to respond when they have affective knowledge is all too often taken a step too far, leading many to assume that affective knowledge must be based in personal and localized risk assessment, or that people will only act when 
they perceive personal risk. This view was made apparent to me during one of my interviews with a communications staffer at one of Sweden’s most influential environmental organizations, who said, We know that people make changes when they feel the effects of environmental problems closer to home. Then they will act . . it becomes important to their welfare, to their family. But before people see those signs and feel damage, they won't do anything.

Based in the frequent conflation of risk and self-interest and thus the assumption that risk is only relevant when it directly affects individual welfare, these ideas have long been perpetuated within western studies of economics. Szerszynski \& Urry argue that the discipline of economics has "largely monopolized the way that the social is conceived in the discourses of climate change. It has led to a focus on human practices as individualistic, market-based, and calculative, and has thus helped to strengthen a tendency towards a certain set of responses to climate change, ones based on individual calculation, technology and the development of new markets” (2010:3). The outgrowth of this conflation of risk and self interest is that sustainability programs and politics are designed to appeal to rational and singular individuals, and thus focus on informational campaigns and soft policies that offer financial incentives designed to reduce the costs of pro-environmental behaviors (OECD 2011). Yet these programs have not generated sufficient response.

It is certainly easy to claim that people don't respond to climate change because it is not in their self interest - because they don't feel personally affected by these issues and acting on them would be more costly than beneficial, but this is a dangerous generalization. Cultivation theory suggests that in the US context, where skepticism abounds, citizens have been cultivated to believe that humans are all self-interested and will not respond to climate change unless one is at personal risk. When we do not trust others - either other individuals or corporations and governments - to act in the interests of the common good, but rather assume that all will act in their own interests alone, this cultivates similar 
behavior (Flannery 2011) and has the potential to become a self-fulfilling prophesy. If policy makers and environmental groups assume that people will not act without experiencing or perceiving personal risk, they may discount their ability to influence change.

In a related point, the individualist framing of climate perception and action neglects significant concern for social welfare and climate justice. Several studies have suggested that concerns for equity and environmental justice have more resonance with people than the rationalization of lifestyles or appeals to self-interest (Author 2010, Berglund \& Matti 2006, Hobson 2002). Indeed it appears that the social risks associated with climate change are often considered more serious than individual risks in multiple international contexts, including Germany (Zwick \& Renn 2002), Italy and the UK (Lorenzoni 2003). Bord and colleagues (1998) found that high levels of concern about the climate reported in surveys are often tapping into social rather than individualist concerns (Lorenzoni and Pidgeon 2006). Yet Giddens' framing of a paradox, predicated on local and personal risk experiences neglect these concerns for environmental justice.

Stories and images of Arctic communities challenged by rapidly disappearing coastlines, of melting glaciers in the Bolivian highlands and of Nigerian communities surrounded by encroaching sand dunes have helped to illustrate the contemporary and potential effects of climate change. These stories give the elusive and seemingly intangible phenomenon of climate change a human face, complete with tales of both human struggle and perseverance. At the same time, these stories also point to the cruel irony and injustice of climate change. While the world's wealthiest nations are disproportionately responsible for cumulative global greenhouse gas emissions and the highest per capita emissions (IPCC 2007), projections indicate that the people least likely to have contributed to the problem are more likely to be negatively affected (Crate \& Nutttall 2009, Marino \& Ribot 2012). They are rural communities 
dependent on agriculture, island nations vulnerable to sea-level rise, and mountainous communities dependent on fresh water from diminishing glaciers.

Humans have the capacity to understand and react to perceptions of environmental risk from afar as demonstrated by the climate conscious Swedes participating in this research, many of whom were motivated by moral concerns for global and generational equality and fairness. These men and women have acted, often very progressively, despite the fact that they feel no personal risk and have rarely witnessed environmental degradation first hand. After all, Swedes enjoy a relatively clean environment thanks to progressive environmental policies. Yet, they clearly do not discount the future or illustrate Giddens’ paradox. It seems that concerns for equality, and “just sustainabilities” (Agyman et. al. 2003) can extend beyond national boundaries. We must remind ourselves that affective knowledge and selfinterest should not be conflated. People can have emotional and associative responses to displaced climate risks, particularly if they hold broader definitions of community and place.

Another, related problem with Giddens' Paradox, as it is currently framed, is that it risks depoliticizing climate knowledge and neglects growing evidence that our views about the climate are more closely linked to political ideologies and our cultural locations on the polemic between individualist and collectivist ethos. Several recent books and articles suggest that climate knowledge has been heavily politicized (Hansen 2009, Hulme 2009, Lahsen 2008, Oreskes \& Conway 2010, Dunlap \& McCright 2008, Withmarsh 2011, Mann 2012), particularly in the United States where the percentage of citizens who believe in climate change has plummeted from $71 \%$ in 2007 to $41 \%$ in 2012, largely along political party lines (Asquith 2012). Understanding this politicization and the influence of special interests is a useful perspective for explaining differences in public attitudes toward climate change in different national contexts. 
As Naoimi Klein argues, climate change threatens free-market worldviews and dominant discourses linked to freedom and individual rights. As such, Klein contends, skepticism is linked to a growing recognition that climate change means we will have to throw out the "free market playbook" (Asquith 2012) and begin to more closely regulate the fossil fuel industry and enery sectors. Perhaps Sweden’s long tradition of state regulated capitalism and trust in the government's ability to oversee the economy leaves Swedes more open to the idea of governmental regulation. But for other nations more vested in the ideology of market freedom and for the powerful with a vested intereste in continued fossil fuel combustion, climate change and governmental intervention are viewed with great skepticism. Zahran and colleagues (2008), for example, have demonstrated that the likelihood of participating in the Cities for Climate Protection program is heavily influenced by the percentage of the residents employed in the fossil fuel industry and political party. Beck writes, "if we want to locate climate change at the heart of sociology and politics, we have to link it internally to the power and conflict dynamics of social inequalities: where does the power of and resistance against climate politics come from?” (2010:257). Without a consideration of the powerful interests that defend ideologies of fossil fueled growth, Giddens' paradox depoliticizes climate risk perception and response - and thus misses a large part of the equation.

Conclusion: Reframing Affection in a Global Community My point here is not that the insights that inform Giddens paradox are wrong, but rather that they are too simple as they've been appropriated by Giddens and framed in popular discourse (Bunting 2010, Monibot 2009) . There are other factors, linked to political culture, history, and deeply embedded cultural beliefs and values, that influence our perceptions of risk and ideas about appropriate response (Swim et. al. 2010).

An amazing number of theories have been proposed to explain climate inaction (Gifford 2010, Kollmuss \& Agyeman 2002), yet there are no universal explanations. Indeed the structural, cultural, 
political and psychological factors that prevent and motivate more ambitious climate action are complex. Yet despite this and the widespread recognition that risk perception is constructed, unstable and contested (Caplan 2000, Douglas 1992, Rappaport 1988, Kempton \& Holland 2001), many commentators stand by generalized, depoliticized and ahistorical claims that most humans won't respond to climate risks until they experience them first hand. But we must be careful not to conflate risk perception with self interest or to assume that affective knowledge can only be generated by localized risks that affront personal security.

Several authors have recently pointed out the possibilities for climate change to reframe how we think about human society. Ulrich Beck has argued that climate change releases a "cosmopolitan momentum" that transcends national borders and can go beyond usual categorizations of the self and other, the domestic and the foreign, to create a greater sense of interconnection and dependency (2010). Similarly Mike Hulme argues that climate change provides the opportunity for fundamentally reimagining human nature and our relationships to one another and our natural surroundings. While this might all seem overly idealistic, I think it is certainly worth exploring given the Swedish case. Many of the men and women participating in my research had made drastic reductions in their $\mathrm{CO} 2$ emissions by boycotting air travel, selling their cars, implementing energy efficiency measures in their homes, and by buying local, second hand and less overall. Yet many of these men and women, and particularly the most progressive among them, were not motivated by a sense of personal risk or the promise of economic savings. Their decisions were instead motivated by a more cosmopolitian conceptualization of risk that included concerns for global equity and climate justice. There is certainly the possibility that our imaginations can be expanded onto larger scales; that we can equate place with the entire planet and risk with all of humanity even if in reality we act locally and our efficacy is uneven. Sheila Jasanoff has written, "To be sure, shifting the scale of an environmental problem up to the global level does not 
necessarily entail losses of meaning or caring. Ideas of belonging and stewardship can develop on a planetary scale” (2010:242).

The Swedish example illustrates that perhaps a more cosmopolitian and global framing of climate risk can motivate more meaningful change. So despite a tendency to discount temporally and spatially distant risks, we should not assume that the absence of personal risk prevents climate action. After all, this assumption essentially disempowers policy makers and educators, leaving few options for motivating action, other than appeals to self-interest. Instead of continuing with the assumption that risk and response are essentially about self interest, perhaps we might also consider the possibility of motivating more significant change through improved awareness of the social effects of climate change and injustice. This implies not only a shift in educational campaigns but that we also empower people to move beyond the reduced costs and efficiency promised by "green" consumerism and market-based solutions, to engage in the public realm as citizens demanding more significant structural changes, effective policy and the more equitable distribution of climate risks and benefits. As Beck writes, "Social inequalities and climate change are two sides of the same coin" that cannot be considered in isolation given the effects of power on climate change and the reciprocal influence of climate change on inequality and injustice (2010:xx). 


\section{Works Cited}

Asquith, C. 2012. Throwing out the Free Market Playbook: An Interview with Naomi Klein. Solutions Volume 3(1).

Baker, S. and K.Eckerberg, eds., 2007. In Pursuit of Sustainable Development: New Governance Practices at the Sub-National Level In Europe. ECPR Studies in European Political Science: Routledge.

Beck, U., 2010. Climate for Change, or How to Create a Green Modernity? Theory Culture Society $2010 ; 27 ; 254$

Berglund, C. and S. Matti, 2006. Citizen and Consumer: The Dual Role of Individuals in Environmental Policy, Environmental Politics 15(4): 550-571.

Binkley, S. 2008. Liquid Consumption: Anti-Consumerism and the Fetishized De-Fitishization of Commodities. Cultural Studies 22(5):599-623.

Broadbent, J. 2009. What does Sociology bring to the table for studying the human dimensions of global climate change? Workshop on Sociologocal Perspectives on Global Climate Change http://ireswb.cc.ku.edu/ crgc/NSFWorkshop/Readings/NSF_WkspReport_09.pdf

Brody, S. D., Zahran, S., Vedlitz, A. \& Grover, H. 2008. Examining the relationship between physical vulnerability and public perceptions of global climate change in the United States. Environ. Behav. 41, 72-95. 
Brugger, J. 2010. Why Americans Don’t Believe in Climate Change. Paper presented at the American Anthropological Association Meetings, November 2010: New Orleans.

Bunting, Madeline. In this remote town in Mali, climate change takes on a sinister reality

. The Guardian November 1, 2010. http://www.guardian.co.uk/commentisfree/2010/oct/31/climate-change$\underline{\text { mali-africa-aid }}$

Castree, N. (2010) ‘Extended review: The paradoxical Professor Giddens’, The Sociological Review, 58(1): 156-162.

Caplan, P. 2000. Risk Revisited: Anthropology, Culture and Society. London: Pluto Press.

Crate, S. A,, and M. Nuttall. 2009. Anthropology and Climate Change: From Encounters to Actions. Walnut Creek, CA: Left Coast Press.

European Commission. 2009a. Europeans' Attitudes toward Climate Change [online]. European Commission. Available from: http://ec.europa.eu/public_opinion/archives/ebs/ebs_313_en.pdf [accessed April 17, 2012].

European Commission 2009b. Public Opinion in the European Union [online]. National Report Executive Summary, Sweden. European Commission Brussels, Belgium. Available from: http://ec.europa.eu/public_opinion/archives/eb/eb72/eb72_se_en_exec.pdf [accessed April 17, 2012]. 
Douglas, M. 1992. Risk and Blame: Essays in Cultural Theory. New York: Routledge.

Dunlap, R., McCright, A.M., 2008. A widening gap: Republican and Democratic views on climate change. Environment 50, 26-35.

European Environmental Agency. 2012. Greenhouse Gas Data Viewer. http://www.eea.europa.eu/dataand-maps/data/data-viewers/greenhouse-gases-viewer

European Union. 2012. Environment: Protecting and Improving the Planet [online]. Available from: http://europa.eu/pol/env/index_en.htm [accessed April 17, 2012].

Eurostat. 2012. CO2 emissions per inhabitant in the EU and in developing countries. European Commision. http://epp.eurostat.ec.europa.eu/portal/page/portal/environment/data/main_tables

Erickson, R. J. 1997. Paper or Plastic: Energy, Environment and Consumerism in Sweden and America. Westport, Connecticut: Praeger.

Feichtinger, J. and M. Pregernig. 2005. Imagined Citizens and Participation: Local Agenda 21 in Two Communities in Sweden and Australia. Local Environment 10 (3):229-242.

Flannery, T. 2011. Here on Earth: A Natural History of the Planet. Altantic Monthly Press.

Frykman, J. and O. Löfgren (1987). Culture Builders: A Historical Anthropology of Middle Class Life. Rutgers University Press. 
Gallup Opinion Polls . 2008. Top Emitting Countries Differ on Climate Threat [online]. Available from: http://www.gallup.com/poll/124595/top-emitting-countries-differ-climate-change-threat.aspx\#2 [accessed April 17, 2012].

Global Footprint Network. 2012. Footprint for Nations [online] Available from: http://www.footprintnetwork.org/en/index.php/GFN/page/footprint_for_nations/ [accessed April 17, 2012].

Giddens, A. 2009. The Politics of Climate Change. Polity Press.

Gifford, R. 2011. The dragons of inaction: Psychological barriers that limit climate change mitigation and adaptation. American Psychologist 66(4):

Gifford, R., Scannell, L., Kormos, C., Smolova, L., Biel, A., Boncu, S., et al. (2009). Temporal pessimism and spatial optimism in environmental assessments: An 18-nation study. Journal of Environmental Psychology, 29, 1-12.

Guggenheim, D. 2006. An Inconvenient Truth: A Global Warning [DVD]. Hollywood: Paramount.

Hansen, J. 2009. Storms of My Grandchildren: The Truth about the Coming Climate Catastrophe and Our Last Chance to Save Humanity. New York: Bloomsbury. 
Harring, N., S.C. Jagers, and J.Martinsson. 2011. Effects of Ecological Modernization, the Economy, and the Media. Organization Environment

Hobson, K. 2006. Bins, Bulbs, and Shower Timers: On the ‘Techno-Ethics’ of Sustainable Living. Ethics, Place and Environment 9(3):317-336, October 2006

Hobson, K. 2002. Competing discourses of sustainable consumption: does the 'rationalization of lifestyles' make sense? Environmental Politics 11(2): 95-120.

Hulme, M. 2010. Cosmopolitan Climates: Hybridity, Foresight and Meaning Theory Culture Society 27: 267.

Jagers, S. and J. Martinsson. 2007. Svensk Opinion i Klimat- och Havsmiljofagor: Nya Siffor fran SOM-Institutet. Goteborgs Universitet, SOM Institutet.

Jasanoff, S. 2010. A New Climate for Society. Theory Culture Society 27:233.

Jörby, S. A. 2002. Local Agenda 21 in Four Swedish Municipalities: A Tool Towards Sustainability? Journal of Environmental Planning and Management 45(2):219-244.

Kahan, D.M., Jenkins-Smith, H. and Braman, D 2011. Cultural Cognition of Scientific Consensus. Journal of Risk Research 14, 147-174. 
Kempton, W., D. Holland, K. Bunting-Howarth, E. Hannon, and C. Payne. 2001. Local Environmental Groups: A Systematic Enumeration in Two Geographical Areas. Rural Sociology 66(4):557-578.

Khakee, A. 2002. Assessing Institutional Capital Building in a Local Agenda 21 Process in Göteborg.’ Planning Theory and Practice Vol. 3, No. 1, Pgs. 53-68.

Kollmuss, A. \& Agyeman, J. Mind the gap: Why do people act environmentally and what are the barriers to pro-environmental behaviour. Environ. Educ. Res. 8, 239-260 (2002).

Konsumentverket. 2001. Miljö för Mljarder: Om Rättvis Konsumption i ett Global Perspektiv. Karlstad, Sweden: Konsumentverket.

Lahsen, Myanna. 2008. “Experiences of Modernity in the Greenhouse: A Cultural Analysis of a Physicist “Trio”Supporting the Backlash Against Global Warming.” Global Environmental Change 18:204-219.

Lee, M. S.W., K.V. Fernandez, M. R. Hyman. 2009. Anti-consumption: An overview and research agenda. Journal of Business Research 62(2):145-147.

Lorenzoni, I., Hulme, M. (2009) Believing is seeing: Laypeople’s views of future socioeconomic and climate change in England and in Italy. Public Understanding of Science, 18 (4) pp. 383-400. 
Lorenzoni, L. and N. Pidgeon. 2006. Public Views on Climate Change: European and USA Perspectives. Climatic Change 77: 73-95

Löfgren, O. 2001. Know Your Country: A Comparative Perspective on Tourism and Nation Building in Sweden. In Being Elsewhere: Tourism, Consumer Culture, and Identity in Modern Europe and North America. Baranowski and Furlough, eds. University of Michigan Press, Pgs. 137-154. Löfgren, O (1990) Landscapes and Mindscapes. Folk 31:183-208

Mann, M. 2012. The Hockey Stick and the Climate Wars: Dispatches from the Front Lines. New York: Columbia University Press.

Matti, S. 2005.A Swedish Environmental Norm? Exploring the Normative Foundations of Swedish Environmental Policy. SHARP Working Paper 3, SHARP Research Progamme.

Matti, S. 2009. Exploring Public Policy Legitimacy: A Study of Belief-System Correspondence in Swedish Environmental Policy. Doctoral thesis Luleå: Luleå Tekniska Universitet.

McCright, Aaron M. and Riley E. Dunlap. 2003. “Defeating Kyoto: The Conservative Movement’s Impact on U.S. Climate Change Policy.” Social Problems 50:348-373.

Monibot, George. 2009. Stop Building Tanks. The Guardian . June 23 ${ }^{\text {rd }}$, 2009. Available from, http://www.monbiot.com/2009/06/23/stop-building-tanks/ [accessed August 8, 2012]. 
Naturvårdsverket. 2012. National Inventory Report: Sweden 2012 [online]. Submitted under the United Nations Framework Convention on Climate Change and the Kyoto Protocol. Stockholm: Naturvårdsverket. Available from:http://www.naturvardsverket.se/upload/11_statistik/vaxthusgaser/ 2012/NIR/NIR_submission_2012.pdf [accessed April 17, 2012].

Naturvårdsverket. 2010. The Climate Impact of Swedish Consumption [online]. Available at : www.naturvardsverket.se [accessed April 10, 2010].

Naturvårdsverket. 2009. Allmänheten och Klimat Förändringen 2009, Rapport 6311. Stockholm, Sweden.

Naturvårdsverket. 1996. Biff och bil? Om hushållens Miljöval [online]. Available from: http://www.naturvards verket.se [accessed May $18^{\text {th }} 2008$ ].

Organization for Economic Co-Operation and Development (OECD). 2008. Promoting Sustainable Consumption: Good Practices in OECD Countries [online]. Available from: http://www.oecd.org/dataoecd/1/59/40317373.pdf [accessed November 28, 2011]

Oreskes N. \& E. Conway. 2010. Merchants of Doubt: How a Handful of Scientists Obscured the Truth on Issues from Tobacco Smoke to Global Warming. Bloomsbury Press.

Rapport, R. 1988. Toward Postmodern Risk Analysis. Risk Analysis 8(2):189-191. 
Rowe, J. and C. Fudge. 2003. Linking National Sustainable Development Strategy and Local Implementation: A Case Study in Sweden. Local Environment 8(2):120-148.

_Semenza, J.C., G.B. Ploubidis \& L.A. George. 2011. Climate change and climate variability: personal motivation for adaptation and mitigation. Environmental Health 2011, 10:46

Spence, A., W. Poortinga, C. Butler \& N. F. Pidgeon. 2011. Perceptions of climate change and willingness to save energy related to flood experience. Nature Climate Change 1, 46-49

Stern, N. 2006. Stern Review Report on the Economics of Climate Change. London: HM Treasury.

Stockholmstad. 2009. Analysis of traffi c in Stockholm with special focus on the effects of the congestion tax, 2005-2008. City of Stockholm Traffic Administration.

Swim, J., P. Stern, T. Doherty, S.Clayton, J. Reser, E. Weber, R. Gifford, G. Howard (2011) Psychology's Contributions to Understanding and Addressing Global Climate Change. American Psychologist 66(4): Special issue: Psychology and Global Climate Change.

Swim, J., S. Clayton,T. Doherty, R. Gifford, G. Howard, J. Reser, P. Stern, and E. Weber (2010) Psychology and Global Climate Change: Addressing a Multi-faceted Phenomenon and Set of Challenges. American Psychological Association http://www.apa.org/science/about/publications/climate-change.aspx

Szerszynski , B. and J. Urry. 2010. Changing Climates: Introduction. Theory Culture Society 27:1. 
United States Environmental Protection Agency. 2012. Greenhouse Gas Emissions [online]. United States Environmental Protection Agency. Available from: http://www.epa.gov/climatechange/emissions/ [accessed April 17, 2012].

Uzzell, D. L. (2000). The psycho-spatial dimensions of global environmental problems. Journal of Environmental Psychology, 20(4), 307-318.

Weber, E. U. (2006). Evidence-based and description-based perceptions of long-term risk: Why global warming does not scare us (yet). Climatic Change, 77, 103-120.

Wissenburg, M. 1993. The Idea of nature and the nature of distributive justice. In, The politics of nature, Dobson \& Lucardie eds., Pgs. 3-20. London: Routledge.

World Watch Institute. 2010. State of the World: Transforming Cultures From Consumption to Sustainability.

Yale Center for Environmental Law \& Policy, and Center for International Earth Science Information Network at Columbia University. "Environmental Performance Index

Zahran, S., Brody, S. D., Vedlitz, A., Grover, H., and Miller, C., 2008. Vulnerability and capacity: explaining local commitment to climate-change policy. Environment \& Planning C: Government \& Policy, 26(3), 544-562 
Zahran, S., Brody, S., Grover, H., \& Vedlitz, A., 2006. Climate Change Vulnerability and Policy

Support. Society \& Natural Resources, 19(9), 771-789 


\section{TABLES}

\begin{tabular}{|l|l|}
\hline TABLE 1 - Categories of "Sustainable" Actions Listed & $88 \%$ \\
\hline Food (buy organic, local, less meat, sustainable fish, free range) & $86 \%$ \\
\hline Travel (fly \& drive less, public transport, walk, bike) & $66 \%$ \\
\hline Buy less stuff (cut back consumption, less stuff) & $60 \%$ \\
\hline Improve home efficiency (short showers, full loads, light bulbs, lights out) & $47 \%$ \\
\hline Reduce Waste (less packaging, recycle, compost) & $47 \%$ \\
\hline Cooperate (cooperative living, borrow, trade services) & $45 \%$ \\
\hline Use alternative technologies (appliances, cars, alternative energy) & $45 \%$ \\
\hline Educate yourself (do research, read newspapers, attend conferences) & $38 \%$ \\
\hline Change values (prioritize, think about what is important) & $33 \%$ \\
\hline Advocate (educate children, friends, blog, etc) & $28 \%$ \\
\hline Citizenship (vote, demonstrate, communicate to leaders) & $28 \%$ \\
\hline Join groups (support, join, get active) & $28 \%$ \\
\hline Do it yourself (grow/cook your own food, make things) & $22 \%$ \\
\hline Avoid chemicals (fewer cleaners, eco-labeled products, lawn chemicals) & $22 \%$ \\
\hline Reuse/ Repair (make things last longer, use what you have, get creative) & $21 \%$ \\
\hline Buy used (second hand, vintage, retro) & $17 \%$ \\
\hline Buy quality (longer life, high price, fair labor) & $10 \%$ \\
\hline Demand alternatives (talk to retailers, producers) & $9 \%$ \\
\hline Work less (work fewer hours, less money, more time with family/friends) & $2 \%$ \\
\hline Invest green (invest in environmentally responsible businesses) & \\
\hline
\end{tabular}

